\title{
Experimental studies of the recombination processes in II-VI semiconductors (bulk crystals and epilayers) at variable excitation levels
}

\author{
M.S.Brodyn, S.G.Shevel, V.V.Tishchenko \\ Institute of Physics of the National Academy of Sciences of Ukraine, \\ 46 Nauky Avenue, 252022 Kyiv, Ukraine
}

Received April 21, 1998

\begin{abstract}
Low-temperature luminescence spectra under broad-scale variation of an excitation level $\mathrm{I}_{\text {exc }}$ are studied for $\mathrm{ZnS} / \mathrm{ZnSe}$ single quantum wells (QW) and for CdS bulk crystals and epilayers. In the first case, the manifestations turn out to be of the heterointerface inhomogeneity - i.e. fluctuations of QW thickness. The position of the mobility edge for excitons localized by fluctuations is determined. In the second case the effect of the increase of $I_{\text {exc }}$ is systematically studied not only for excitonic but also for impurity-related edge luminescence. Contrary to the earlier and commonly assumed expectations, up to the highest $l_{\text {exc }}$ close to damage threshold no saturation of edge luminescence intensity was observed in bulk CdS crystals, whereas in a few thick epilayers such saturation did occur. The suggested qualitative explanation takes into account diffusion (non-diffusive transport) of carriers beyond the excited near-surface layer.
\end{abstract}

Key words: luminescence,quantum well,epilayer, exciton, ZnSe, CdS

PACS: $78.20 .-e$

\section{Introduction}

From the mid-sixties till early eighties much work was done towards the understanding of the behaviour of carriers (excitons) in bulk direct-gap II-VI crystals with the increase of optical excitation level $\mathrm{I}_{\text {exc }}$. The results are reviewed, e.g. in $[1,2]$. With the later advance of growth techniques to fabricate high-quality epilayers and quantum well (QW) structures the interest in the above-mentioned field has grown anew, see, e.g. [3,4] and references therein. This interest is largely applicationmotivated, especially after the demonstration of ZnCdSe-based laser diode operating in the blue-green [5]. Besides, some relevant problems of fundamental importance remained relatively unexplored and require a better insight. 
In the numerous spectroscopic studies of high-excitation phenomena, the attention was mostly focused on the various collective processes with participation of excitons as manifested in the occurrence of new bands in the excitonic part of the near-edge emission spectrum with the increase of $\mathrm{I}_{\text {exc }}[1,2]$. In the present work we shall try to demonstrate that the studies of emission spectra under variable $\mathrm{I}_{\text {exc }}$ could provide a valuable information regarding the intrinsic properties of carriers (excitons) as well. The objects under study are the epitaxial layer structures with a different confinement scale.

\section{Results and discussion}

\subsection{ZnSe-ZnS QW structures}

In the first part of the paper the results are discussed for ZnSe-ZnS single QW on GaAs substrate. Single $11 \AA$ - thick ZnSe QW's sandwiched between wider-gap ZnS barrier layers of $54 \AA$ thickness were grown by a relatively simple, inexpensive and flexible technique of photo-assisted vapour phase epitaxy - PAVPE. The details of the growth procedure are reported elsewhere [6]. The obtained structures are coherently strained since the thickness of the layers is smaller than the respective critical values of about $100 \AA$ when mismatch dislocations emerge. Consequently, the small variations in QW thickness do not cause the change of deformation within the layer plane.

In quite many earlier works carried out for QW structures grown by other epitaxial techniques like MBE and MOCVD it was shown that the heterointerface disorder (fluctuations $\delta L_{z}$ in QW thickness) resulted in the inhomogeneous broadening of excitonic photoluminescence (PL) band [7-10]. In the highest quality structures $\delta L_{z}$ corresponds to a single atomic layer.

In our case the properties of excitonic PL were studied under excitation by 325 $\mathrm{nm}$ line of cw He-Cd laser (average power $\left(10 \mathrm{~mW}\right.$ ). The intensity $\mathrm{I}_{\mathrm{exc}}$ on the sample surface varied over about three orders of magnitude. The spectra were registered by photon-counting technique.

In figure 1 plot "a" represents an "integrated" (taken with the excitation spot diameter $\mathrm{d}=2 \mathrm{~mm}$ to cover the entire sample surface) PL spectrum typical for all QW under study. The emission is of excitonic nature as it is evident from the comparison with the low-temperature exciton reflection curve - plot "e" in figure 1. The spectra are shifted by $\sim 188 \mathrm{meV}$ to higher energies in comparison with their positions known for bulk ZnSe. This short-wavelength shift is caused by the combined effect of size quantization and elastic stress deformation. The latter is due to lattice mismatch between $\mathrm{ZnSe} / \mathrm{ZnS}$ and GaAs substrate; the deformation contribution into the observed shift does not exceed $5 \%$ [11].

The peak position $\mathrm{E}_{m}=2.980 \mathrm{eV}\left(\lambda_{m}=415.9 \mathrm{~nm}\right)$ of the excitonic PL band (plot "a" in figure 1) is only weakly sample-dependent whereas the band itself is asymmetric with a number of shoulders. They are not equidistant in energy scale and therefore cannot be assigned to phonon replicas. Taking also into account the 


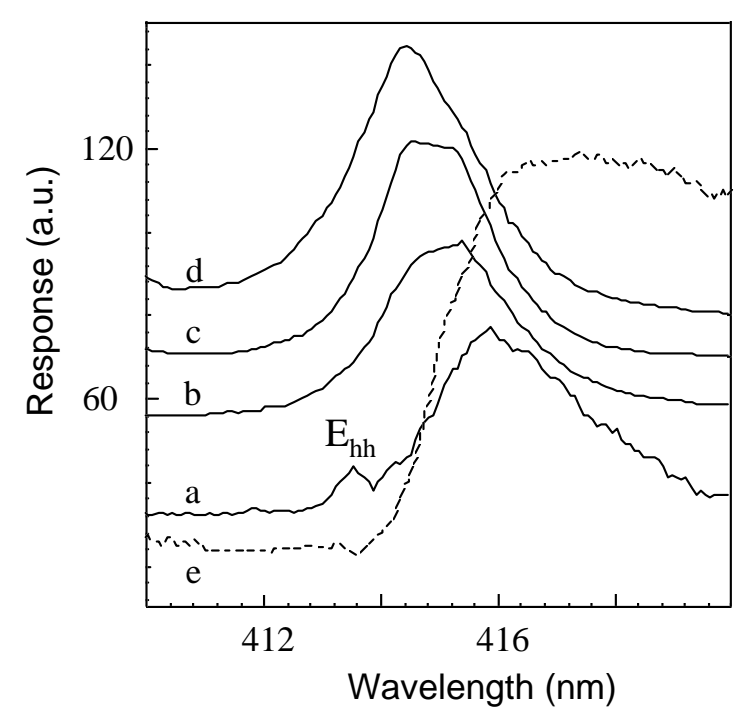

Figure 1. Spectra of integrated (a) and local (b-d) photoluminescence and reflection curve (e) for ZnSe-ZnS QW at T=4.5 K. The spectra $\mathrm{b}$ to $\mathrm{d}$ were measured at different excitation spot positions on the sample surface. Excitation level for b-d is 400 times higher than for a. The different plots in this and in other figures are arbitrarily shifted along Y-axis for clarity.

dependence of $\mathrm{E}_{m}$ on the excitation spot position when the spot diameter was made $\mathrm{d}=100 \mu$ - cf. plots $1 \mathrm{~b}, \mathrm{c}$ and $\mathrm{d}-$ it is plausible to attribute the occurrence of shoulders to the inhomogeneity of QW structures under study.

In figure 2 the dependencies of PL spectra taken from different excitation spot positions on $\mathrm{I}_{\mathrm{exc}}$ are illustrated. As a rule, with the increase of $\mathrm{I}_{\mathrm{exc}}$ the peak $\mathrm{E}_{m}$ shifts to higher energies approaching a limit of $2.991 \mathrm{eV}$. Simultaneously, the band acquires additional asymmetry - its low-energy tail becomes more extended. The similar behaviour is observed with the increase of temperature. Noteworthy is the absence of any new bands that could be associated with the collective processes.

The above-described findings are readily explained within the framework of the model of localization of excitons by potential fluctuations resulting from the disorder in the interface between $\mathrm{ZnS}$ and ZnSe layers. Disorder (fluctuations of QW thickness) on the scale of exciton Bohr radius $\mathrm{a}_{\mathrm{B}}$ inevitably results in the emerging of $2 \mathrm{D}$ potential relief and the respective density-of-states tail. The filling of localized tail states is described by Fermi-Dirac statistics [12]. Though excitons behave like bosons on the sufficiently large distances between them, the applicability of these statistics reflects the fact that due to the internal structure of the quasiparticles under discussion every separate well of the relief that has emerged can localize not more than a single exciton provided the characteristic size $R_{\mathrm{S}}$ of the well is comparable to $a_{B}$.

In view of the above-stated, the behaviour represented in figure 2 is viewed as a result of the increase of the value of chemical potential of the degenerate system of localized excitons with the increase of its density. Clearly, at sufficiently high $\mathrm{I}_{\text {exc }}$ the 

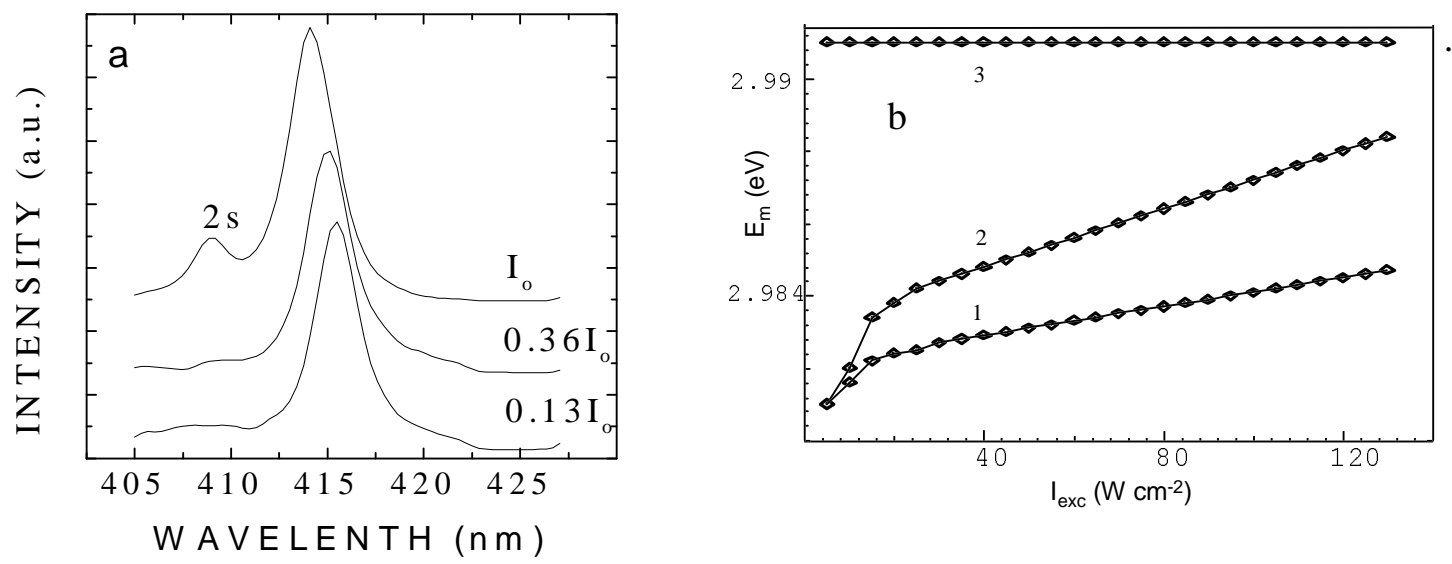

Figure 2. Examples of PL spectra of ZnSe-ZnS QW at different $I_{\text {exc }}$ (a) and the dependencies of the position $\mathrm{E}_{m}$ of PL peak on $\mathrm{I}_{\text {exc }}$ (b). In (a) level $\mathrm{I}_{o}=60$ $\mathrm{W} / \mathrm{cm}^{2}$. In (b) the dependencies 1-3 correspond, respectively, to the curves b-d in figure 1. Points in (b) represent the experimental data whereas the solid lines are the guides for the eye.

chemical potential level may reach the mobility edge $E_{c}$. With the further increase of $\mathrm{I}_{\text {exc }}$ the filling of delocalized states sets in. As a consequence, PL peak becomes stabilized at $\mathrm{E}_{\mathrm{c}}$. The reason for this stabilization is a transition to the statistics with a density-independent distribution function. In contrast to bulk crystals, for 2D QW structures the excitation intensity necessary for such a transition is attainable in real experimental conditions.

From the data in figure 2 we have determined that in our case the mobility edge corresponds to the energy $2.991 \mathrm{eV}$. We also note that the width of PL band (35 to $40 \mathrm{meV}$ on 0.1 intensity level) indicates that $\delta L_{z}$ corresponds to an atomic monolayer.

The key question is the position of $\mathrm{E}_{\mathrm{c}}$ with respect to the free exciton energy. To determine the latter value, a close comparison of the "integrated" PL band (figure 1a) with the reflection curve (figure 1e) is helpful. We draw attention to the weak PL peak at $2.997 \mathrm{eV}(413.5 \AA)$, labelled as $\mathrm{E}_{h h}$ in figure 1a. It is clearly seen only in the PL spectrum integrated over the entire surface and its spectral position falls in the vicinity of the reflection curve minimum (figure 1e). With the precision of the order of the energy of longitudinal-transverse splitting $(1.5 \mathrm{meV}$ for bulk ZnSe [13]) this minimum coincides with the position of free exciton resonance [14]. Therefore we conclude that $\mathrm{E}_{h h}$ peak is due to free exciton recombination in the sample areas of nominal thickness $\mathrm{L}_{z}=11 \AA$. The excitation of the entire surface of the sample as well as the low excitation densities favour the observation of $\mathrm{E}_{h h}$ peak.

It follows from the above attribution that in the samples under study, the mobility edge is $6 \mathrm{meV}$ below the ground state level of h-h exciton in the QW of $11 \AA$ 
thickness (the level of l-h exciton is about $200 \mathrm{meV}$ higher in energy scale [11]).

As regards the nature of delocalized states responsible for the emission within the spectral range from $\mathrm{E}_{\mathrm{c}}$ to $\mathrm{E}_{h h}$, they may be attributed to the exciton states in those QW regions where $\mathrm{R}_{\mathrm{S}}<\mathrm{a}_{\mathrm{B}}[15]$. Excitons move freely within any region of the kind and they experience scattering only on its edges [16]. Then, plot $\mathrm{d}$ in figure 1 is thought to correspond to such areas on the surface where mostly $\mathrm{R}_{\mathrm{s}}<\mathrm{a}_{\mathrm{B}}$.

Therefore the experiments at variable $\mathrm{I}_{\mathrm{exc}}$ enabled us to conclude that the samples under study are inhomogeneous in the sense that the heterointerfaces between QW and barrier layers are disordered as well as the distribution of size $R_{s}$ over the surface is not homogeneous. The latter feature is probably caused by the lateral inhomogeneity of hydrogen flow that is used in PAVPE to carry the reagents to GaAs substrate.

\subsection{CdS epilayers and bulk crystals}

In the second part of the paper we report on the experimental check of how the increase of $\mathrm{I}_{\mathrm{exc}}$ over 6 orders of magnitude affects the behaviour of not only excitonic but also of the so-called "edge" luminescence involving donor-acceptor pairs (DAP).

The objects under study were vapour-grown CdS single platelet crystals with the thicknesses of the order of $40 \mu$ and over, as well as a few thick CdS epilayers grown by hot wall epitaxy [17]. Luminescence was studied mostly at $\mathrm{T}=20 \mathrm{~K}$. The excitation sources were conventional $\mathrm{Hg}$ lamp $\left(365 \mathrm{~nm}\right.$ line, $\left.\mathrm{I}_{\text {exc }} \leqslant 50 \mathrm{~mW} / \mathrm{cm}^{2}\right)$, third harmonic of a Q-switched low-repetition rate $(\sim 4 \mathrm{~Hz})$ YAG: $\mathrm{Nd}^{3+}$ laser with an amplifier stage and UV radiation of $\mu$ s flash lamps. A computer-controlled twochannel digital registration system featured the monitoring of $\mathrm{I}_{\mathrm{exc}}$ in each shot and step-by-step spectral scanning. This approach offered us some advantages like the possibility to adjust the sensitivity on-line when registering spectrally close emission bands of very different intensities, to perform gated detection within the pre-set limits of $I_{\text {exc }}$ to compensate its variations, to measure directly not only spectra but also the dependencies $\mathrm{I}_{\text {lum }}=\mathrm{f}\left(\mathrm{I}_{\text {exc }}\right)$ for the selected emission bands.

Before a further discussion it is helpful to briefly recall the well-established general description of the near-edge radiative recombination channels in CdS (a model object for the entire group of II-VI semiconductors) $[2,18]$. At low $\mathrm{I}_{\text {exc }}$ of the order of $1 \mathrm{~W} / \mathrm{cm}^{2}$ or below, typical features of the excitonic ("blue") luminescence at helium temperatures appear to be a weak free A-exciton band and narrow bands $\mathrm{I}_{2}$ and $\mathrm{I}_{1}$ due to excitons bound on neutral donors and acceptors, respectively, together with their LO-phonon replicas. Non-excitonic recombination of electrons and holes via impurity levels gives rise to the so-called edge ("green") luminescence at longer wavelengths. At helium temperatures, recombination "electron on donor hole on acceptor" prevails. It is manifested by a "long-wavelength (LW)" series zero-phonon band with satellites due to the interaction with LO phonons. At elevated temperatures, electrons escape from relatively shallow donor centers and gradually "short-wavelength (SW)" series due to recombination "free exciton - hole on the same acceptor" becomes dominant.

PL spectra under Hg-lamp excitation for CdS platelet crystal (figure 3) agree 


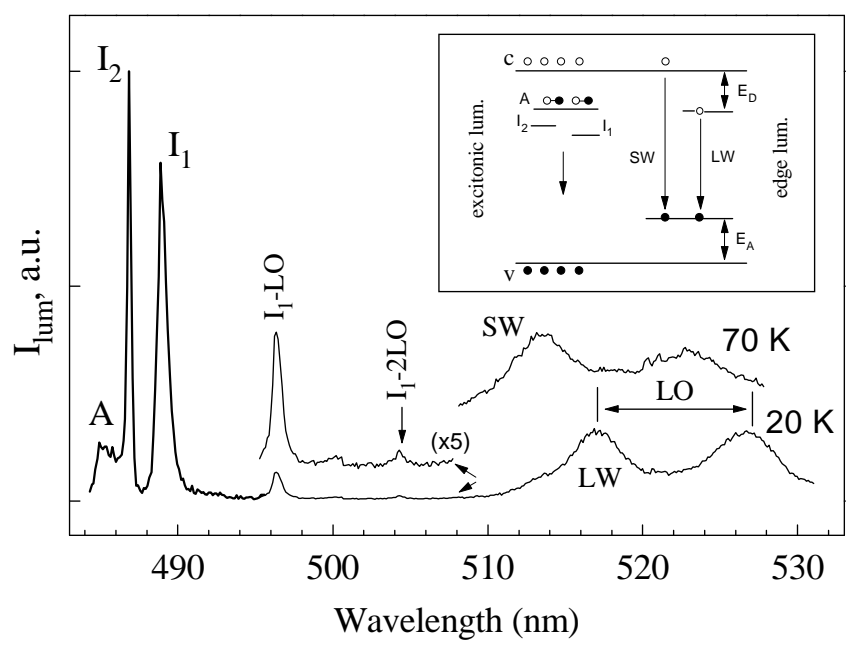

Figure 3. Simplified scheme of the transitions responsible for excitonic and edge luminescence (the insert) and experimental PL spectra at Hg-lamp excitation for CdS platelet crystal at $20 \mathrm{~K}$ and $70 \mathrm{~K}$. In this and in other figures, scaling factors, if different from 1 , are shown in parentheses.

with this recombination scheme (illustrated in the insert). In this case the (net) intensity of the LW band ( $517 \mathrm{~nm}$ ) of the DAP emission was about 2.7 times higher than the intensity of the $\mathrm{I}_{1}$-LO excitonic component $(496.3 \mathrm{~nm})$ and almost 18 times higher in comparison with $\mathrm{I}_{1}-2 \mathrm{LO}(504.3 \mathrm{~nm})$. Evidently, such ratios depend on the content of impurities in a particular sample and sometimes were found to vary slightly with the position of an excitation spot (of about $0.5 \mathrm{~mm}$ diameter) on the surface. In the "high quality" CdS crystals [18] and epilayers [17], edge luminescence and sometimes $\mathrm{I}_{1}$ (not $\mathrm{I}_{2}$ !) excitonic band may not be present at all. In the usual, not intentionally doped platelet CdS crystals used here, the edge luminescence was often present. The basic findings to be discussed below were found to be qualitatively similar in different crystals of the kind. Therefore, the examples in the figures to follow will be given for the same platelet sample as in figure 1 .

Our main aim was to check the behaviour of edge luminescence with the increase of $\mathrm{I}_{\text {exc }}$ up to the highest possible values (a few $\mathrm{MW} / \mathrm{cm}^{2}$ - close to the damage threshold). As already mentioned in the introduction, for excitons in bulk CdS the respective "high-excitation phenomena" were studied in great detail and rather well comprehended. In contrast, the effect of the similar increase of $\mathrm{I}_{\text {exc }}$ on non-excitonic edge luminescence remained quite unexplored. Already in one of the pioneering works on high-excitation phenomena [19], where the model of rate equations had been forwarded to describe the collective processes in highly excited CdS, the assumption was made that the impurity centers involved in DAP emission soon became saturated with the increase of $\mathrm{I}_{\mathrm{exc}}$ and could be neglected. Since then, such a viewpoint has become commonly accepted though, to our knowledge, the saturation of edge emission intensity with the increase of $\mathrm{I}_{\mathrm{exc}}$, in particular, above few tens of $\mathrm{kW} / \mathrm{cm}^{2}$, had never been demonstrated experimentally for either of the II-VI semiconductors. 

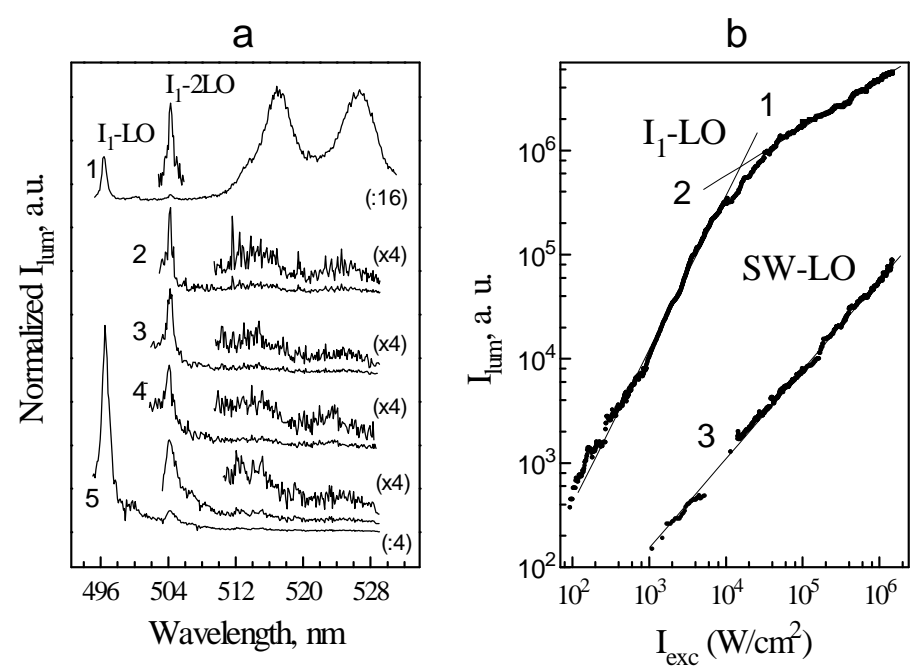

Figure 4. $\mathrm{PL}$ spectra normalized with respect to $\mathrm{I}_{1}-2 \mathrm{LO}$ component (a) and dependencies $\mathrm{I}_{\text {lum }}=\mathrm{f}\left(\mathrm{I}_{\text {exc }}\right)$ for the exciton $\mathrm{I}_{1}-\mathrm{LO}$ band and the first phonon replica SW-LO of edge emission (b) of CdS platelet crystal at $\mathrm{T}=20 \mathrm{~K}$ under excitation by the third harmonic of YAG: $\mathrm{Nd}^{3+}$ laser. Spectra in (a) are taken at the following excitation levels in $\mathrm{W} / \mathrm{cm}^{2}: 1-5 \times 10^{-} 2$ (excitation by Hg-lamp), $2-0.9 \times 10^{3}$, $3-5 \times 10^{3}, 4-3.2 \times 10^{4}, 5-3 \times 10^{5}$. Points in (b) represent the experimental data (after averaging and smoothing), straight lines 1, 2, 3 correspond to a power law $I_{\text {lum }} \propto\left(I_{\text {exc }}\right)^{\gamma}$ with the slopes $\gamma$ ( of 1.48, 0.46 and 0.86 , respectively.

This problem has got wider implications if striving for the comprehensive description of various relaxation channels of radiative and non-radiative recombination, see, e.g. $[1,19,20]$.

The behaviour of excitonic PL with the increase of $\mathrm{I}_{\text {exc }}$ was found to be quite typical, namely, first $I_{2}$ and $I_{1}$ bands become broadened, than the new features due to various exciton scattering processes emerge at different spectral positions until at the highest $\mathrm{I}_{\text {exc }}$ close to damage threshold (few $\mathrm{Mw} / \mathrm{cm}^{2}$ ) ill-structured broad-band emission in the range from $\sim 490 \mathrm{~nm}$ to $\sim 493 \mathrm{~nm}$ dominates. The attributions of the new bands to various collective processes - bI excitons, exciton-exciton inelastic scattering, electron-hole plasma emission at highest $\mathrm{I}_{\text {exc }}$, etc. - are well established though not completely free of controversies [1].

We should emphasize, however, that spectrally isolated phonon replicas $\mathrm{I}_{1}$-LO and $\mathrm{I}_{1}-2 \mathrm{LO}$ were found to survive in the spectra up to the highest $\mathrm{I}_{\text {exc }}$. This confirms the earlier conclusions $[1,21]$ regarding the possibility for the various exciton-related recombination processes to coexist in highly excited II-VI crystals. A possible explanation will be discussed hereinafter. Concerning the edge luminescence, it was found to exhibit a more complicated behaviour with the increase of $\mathrm{I}_{\text {exc }}$ than the simple saturation figures $4 \mathrm{a}, \mathrm{b}$ ). Already at the initial $\mathrm{I}_{\text {exc }}$ of about $1 \mathrm{~kW} / \mathrm{cm}^{2}$ (by the third harmonic of YAG: $\mathrm{Nd}^{3+}$ laser), when excitonic $\mathrm{I}_{2}$ and $\mathrm{I}_{1}$ bands are not yet affected, the relative intensity of edge luminescence drops drastically. Thus, the net intensity of the zero-phonon band of edge emission (the SW-band in this case, see further dis- 
cussion) is more than 20 times weaker in comparison with the excitonic band $\mathrm{I}_{1}-2 \mathrm{LO}$ (e.g., plot 2 in figure 4a). This is in an apparent contrast to the situation with the excitation by $\mathrm{Hg}$ lamp $\left(\mathrm{I}_{\text {exc }} \leqslant 50 \mathrm{~mW} / \mathrm{cm}^{2}\right)$. In fact, without the above-mentioned experimental option of adjusting the sensitivity on-line, we would quite probably miss the weak edge emission whatsoever when registering the neighbouring intense excitonic components.

Notably, no saturation occurs with the further increase of $\mathrm{I}_{\mathrm{exc}}$ of over three orders of magnitude up to a few $\mathrm{MW} / \mathrm{cm}^{2}$. Instead, the intensity of the DAP emission also grows. The growth rate is not very different from that for the excitonic components. This is evident from figure $4 \mathrm{a}$ and - more clearly - from figure $4 \mathrm{~b}$ where the experimental dependencies $\mathrm{I}_{\text {lum }}=\mathrm{f}\left(\mathrm{I}_{\text {exc }}\right)$ (following the averaging and smoothing) are presented. Details on the measurements and on the pre-processing algorithm can be found in [22]). Within certain ranges of $\mathrm{I}_{\mathrm{exc}}$ these dependencies are well approximated by a power law: $I_{\text {lum }} \propto\left(I_{\text {exc }}\right)^{\gamma}$ with $\gamma<2$. In principle, this type of behaviour is obtained (for excitonic bands) in the analytical [22] and in the numerical [23] theoretical calculations as well. Without going into too much details we may note that the obtained experimental results could become helpful when composing the underlying sets of rate equations.

In the additional experiments with the selected microsecond flash lamps as excitation sources we were able to obtain some data in the range of excitation intensities below $1 \mathrm{~kW} / \mathrm{cm}^{2}$. Remarkably, it was found that the initial drop of the relative intensity of DAP emission with respect to excitonic PL becomes noticeable and develops rather fast already at quite moderate - few $\mathrm{W} / \mathrm{cm}^{2}-$ excitation levels, i.e. far below the values when collective processes for excitons show up.

The revealed peculiarities of the edge luminescence behaviour in CdS bulk (platelet) crystals with the increase of $\mathrm{I}_{\mathrm{exc}}$ - fast initial decrease of relative intensity compared to excitonic components but no saturation up to the highest $\mathrm{I}_{\text {exc }}-$ seem to be of common nature. In fact, we have observed the qualitatively similar behaviour for the other (bulk) direct-gap II-VI crystals such as CdSe and $\mathrm{Zn}_{x} \mathrm{Cd}_{1-x} \mathrm{~S}$.

To explain the experimental findings we suggest the qualitative model that takes into account the surface character of a single-photon excitation. Namely, the thickness of the excited near-surface layer, roughly estimated as the inverse of a band-toband absorption coefficient, amounts to $\sim 1 \mu$ or even less [24]. Then the level, say, $10 \mathrm{~W} / \mathrm{cm}^{2}$ of the UV $365 \mathrm{~nm}$ radiation would correspond to the bulk generation rate of electron-hole pairs of about $2 \cdot 10^{24} \mathrm{~cm}^{-} 3 \cdot s^{-} 1$. This is sufficient to saturate the impurity centers of edge luminescence assuming their concentrations to be $10^{16}-10^{17}$ $\mathrm{cm}^{-} 3$ and the radiation lifetimes of the order of tens of nanoseconds or more [25]. Likewise, the rough estimations indicate the possibility of screening the Coulomb interaction for impurity-bound carriers in the near-surface active layer in the same conditions.

At the same time it should be taken into account that with the increase of $\mathrm{I}_{\text {exc }}$ the relative number of carriers becomes larger and they migrate by a diffusion or a non-diffusive [26] transport, driven by an enormous gradient of their chemical potential, to the larger distances from the surface. Then, saturated and/or screened 


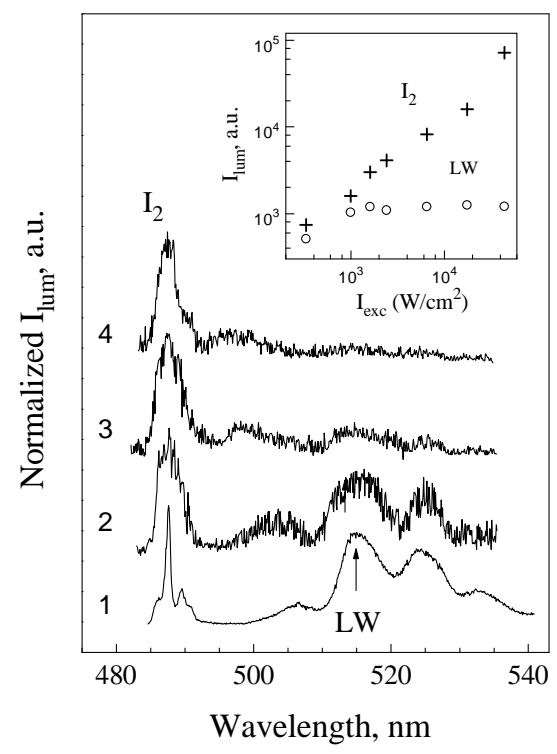

Figure 5. Normalized (with respect to $\mathrm{I}_{2}$ band) luminescence spectra of CdS epilayer at $\mathrm{T}=20 \mathrm{~K}$ under excitation by Hg-lamp (1) and the third harmonic of YAG: $\mathrm{Nd}^{3+}$ laser $(2,3,4)$. Excitation levels in $\mathrm{W} / \mathrm{cm}^{2}$ are, respectively: 1 $0.05,2-1 \times 10^{3}, 3-17 \times 10^{3}, 4-44 \times 10^{3}$. The insert - dependencies $\mathrm{I}_{\text {lum }}=\mathrm{f}\left(\mathrm{I}_{\text {exc }}\right)$ measured as described in the text for excitonic band $\mathrm{I}_{2}$ (crosses) and zero-phonon DAP emission band at $\sim 550 \mathrm{~nm}$ (circles).

impurity centers of edge luminescence in the active near-surface layer coexist with the deeper parts of the crystal where the concentration of the excited carriers is smaller while edge luminescence (relatively weakened) as well as (not self-absorbed) excitonic bands $\mathrm{I}_{1}-\mathrm{LO}$ and $\mathrm{I}_{1}-2 \mathrm{LO}$ follow the increase of $\mathrm{I}_{\text {exc }}$. Such a qualitative model agrees with the experimental observations. It also provides the explanation for the transition from the LW to the SW series with the increase of $\mathrm{I}_{\text {exc }}$ (cf. figure $4 \mathrm{a}$ and figure 3) if a reasonable additional assumption is made that the donors involved are accumulated mainly near the surface in the growth process whereas in the bulk their content is smaller. The fast initial drop of the relative intensity of edge luminescence finds a consistent explanation as the one resulting from the saturation within the near-surface layer before the essential transport inside the crystal sets in.

To verify the suggested model we have performed additional experiments with CdS epilayers. The motivation was obvious: if the above considerations are true, then sufficiently thin (of the order of diffusion length, i.e. a few microns) crystalline layers could be excited almost homogeneously and, in contrast to thick bulk crystals, the saturation of edge luminescence with the increase of $\mathrm{I}_{\text {exc }}$ could be observed. As far as excitons are concerned, they could reach the interface to the GaAs substrate and recombine there.

We have, indeed, observed the expected behaviour for CdS epilayer of $(4 \mu-$ thickness - figure 5). The dependencies $I_{l u m}=f\left(I_{\text {exc }}\right)$ (the insert in figure 5) were obtained in this case by monitoring the intensities of the respective bands $-\mathrm{I}_{2}$ peak 
at $\sim 470 \mathrm{~nm}$ and sim515-nm zero-phonon band of DAP emission - in a sequence of spectra measured at different $\mathrm{I}_{\text {exc }}$ with $\pm 10 \%$ gate. The difference in the spectral position of the zero-phonon edge luminescence band $(\sim 515 \mathrm{~nm})$ in comparison with the LW-band in bulk crystals $(\sim 517.5 \mathrm{~nm})$ could be connected with the different type of donor or some strain in the layer. The possible origin of the emission (that shifts appreciably to shorter wavelength with the increase of $\mathrm{I}_{\mathrm{exc}}$ ) in the "intermediate" spectral range between $\mathrm{I}_{2}$ and 515-nm bands is not clear yet. By an apparent contrast to the bulk crystal, the unambiguous saturation of the zero-phonon band of DAP luminescence was achieved (at $\mathrm{I}_{\text {exc }}$ above $\sim 2 \mathrm{~kW} / \mathrm{cm}^{2}$ ).

\section{Acknowledgements}

This work was supported in part by INTAS program within the project 94-324 and by the Fundamental Research State Fund, Ukraine (grant 2.4/86).

We are grateful to A.Kovalenko, M.Vytrikhivski, M. Grün and M.Hetterich for providing the samples for the present studies, to M.Bondar and V.Vozny for the assistance in the experiments and to Prof. C.Klingshirn for stimulating discussions.

\section{References}

1. Klingshirn C., Haug H. Optical properties of highly excited direct-gap semiconductors. // Phys. Reports, 1981, vol. 70, No. 5, p. 315-398.

2. Klingshirn C. Semiconductor Optics. Springer, Berlin, 1995.

3. Gunshor R.I., Nurmikko A.V., Kolodzejski L.A., Otsuka N. Wide-gap II-VI heterostructures (Invited paper). // Journ. Cryst. Growth, 1990, vol. 101, No. 1-4, p. 1422.

4. Klingshirn C., Kalt H., Umlauff M., Petri W., Majumder F.A., Bogdanov S.V., Langbein W., Grün M., Hetterich M., Geyzers K.P., Heuken M., Naumov A., Stanzl H., Gebhardt W. Stimulated emission of II-VI epitaxial layers. // Journ. Cryst. Growth, 1994, vol. 138, No. 1-4, p. 786-790.

5. Haase M.A., Qiu J., De Puydt J.M., Cheng H. Blue-green laser diodes. // Appl. Phys. Lett., 1991, vol. 59, No. 11, p. 1272-1274.

6. Kovalenko A.V., Tishchenko V.V. ZnS-ZnSe-ZnS/GaAs(100) single quantum well structures and $\mathrm{ZnS} / \mathrm{ZnSe} / \mathrm{GaAs}(100)$ superlattices grown by photo-assisted VPE. // Japanese J. Appl. Phys., 1995, vol. 34, Suppl. 34-1, p. 209-211.

7. Kop'ev P.S., Ural'cev I.N., Efros Al.L., Yakovlev D.R., Vinokurova A.V. Quasi-2D excitons localization on island-like extensions of QW width. // Phys.\& Techn. Poluprov., 1988, vol. 22, No. 3, p 424-432 (in Russian).

8. Kalt H., Collet J.H., Baranovskii S.D., Klingshirn C. Dynamics of localized excitons and high-excitation effects in II-VI quantum wells and heterostructures. // Physica B., 1993, vol. 191, p. 90-101.

9. Taguchi T., Kawakami Y., Yamada Y. Interface properties and the effect of strain of ZnSe/Zns strained-layer superlattices. // Physica B., 1993, vol. 191, p. 23-44.

10. Ledentsov N.N., Ivanov S.V., Maksimov V.M., Sedova I.V., Tabadze I.G., Kop'ev P.S. Luminescence of localized e-h pairs in the region of fundamental absorption of 
Zn(S,Se)-(Zn,Cd)Se QW structures. // Phys.\& Techn. Poluprov., 1995, vol. 29, No. 1, p. 65-69 (in Russian).

11. Tishchenko V.V, Raptis Y.S., Anastassakis E., Bondar N.V. Optical Studies of ZnSe$\mathrm{ZnS} / \mathrm{GaAs}(100)$ single quantum wells grown by photo-assisted vapour phase epitaxy. // Sol. St. Comm., 1995, vol. 96, No. 11, p. 793-798.

12. Kash J.A., Zachau M., Mendez E.E., Hong J.M. Fermi-Dirac distribution of excitons in coupled quantum wells. // Phys. Rev. Lett., 1991, vol. 66, No. 17, p. 2247-2250.

13. Merz J.L., Kukimoto H., Nassau, Shiever J.W. Optical properties of substitutional donors in ZnSe. // Phys. Rev. B, 1972, vol. 6, No. 2, p. 545-556.

14. Tossati E., Harbeke G. Anisotropic exciton polaritons. // Nouvo Cimento B, 1974, vol. 22, No. 1, p. 87-109.

15. Ashkinadze B.M., Cohen E., Azra Ron, Pfeiffer L. Microwave modulation of exciton luminescence in GaAs/AlGaAs quantum wells. // Phys. Rev. B., 1993, vol. 47, No. 12, p. 10613-10617.

16. Stolz H., Schwarze D., von der Osten W., Weigmann G. Transient optical alignment and relaxation of excitons in GaAs/AlGaAs quantum wells. // Superlat. and Microstr., 1989, vol.6, No. 3, p. 271-277.

17. Grün M., Hetterich M., Becker U., Giessen H., Klingshirn C. Wurtzite-type CdS and CdSe epitaxial layers. I. Growth and characterization. // Journ. Cryst. Growth, 1994, vol. 141 , No. 2, p. 68-74.

18. Aven M., Prener S.(Eds). Physics and Chemistry of II-VI Compounds. Amsterdam, North-Holland, 1967.

19. Magde B., Mahr H. Kinetics of excitons in at He temperatures. // Phys. Rev. B, 1970, vol. 2, No. 10, p. 4098-4103.

20. Westphäling R., Bauer S., Klingshirn C., Reznitsky A., Verbin S., Photoluminescence quantum efficiency of various ternary II-VI semiconductor solid solutions. // Journ. Cryst. Growth, 1998, vol. 184/185, p. 1072-1075.

21. Brodin M.S., Taranenko L.V., Shevel S.G. Temperature dependence of threshold and mechanisms of laser generation in CdS single crystals under single-photon excitation. // Sov. Journ. Quant. Electron., 1987, vol. 17, No. 12, p. 1548-1551.

22. Brodin M.S., Gushcha A.O, Khotiaintsev V.N, Shevel S.G., Taranenko L.V., Tishchenko V.V. Nonlinearities in excitonic luminescence of direct-gap semiconductors under very low optical excitation levels. // Phys. Stat. Sol. b, 1987, vol. 144, No. 2, p. 863-873.

23. Schmidt T., Daniel G., Lishka K., The excitation power dependence of the near band edge photoluminescence in II-VI semiconductors. // Journ. Cryst. Growth, 1992, vol. 117, No. 1-4, p. 748-752.

24. Brodin M.S., Strashnikova M.I. Optical characteristics of CdS single crystal in the fundamental absorption range and the structure of energy bands. // Soviet Phys.-Sol. St., 1966, vol. 8, No. 3, p. 549-551.

25. Fricke Ch., Heitz R., Hoffmann A., Broser I., Recombination mechanisms in highly doped CdS:In. // Phys. Rev. B, 1994, vol. 49, No. 8, p. 5313-5322.

26. Frigo N.J., Mahr H., Erskine D.J. Application of a two-wavelength picosecond laser to semiconductors. // IEEE Journ. Quant. El., 1982, vol. QE-18, No. 2, p. 192-198. 
Експериментальні дослідження рекомбінаційних процесів у напівпровідниках А2B6 (об'ємні кристали і епітаксійні шари) при варіації рівня збудження

\author{
М.С.Бродин, С.Г.Шевель, В.В.Тищенко \\ Інститут Фізики НАН України \\ пр. Науки 46, 252022, Київ 22, Україна
}

Отримано 21 квітня 1998 р.

Досліджено спектри низькотемпературної люмінесценції при варіації рівня збудження I у широкому діапазоні для одиночних квантових ям (Кя) ZnS/ZnSe та об'ємних кристалів і епітаксійних шарів CdS. У першому випадку знайдено прояви неоднорідності гетерограниці, тобто флуктуацій товщини КЯ. Визначено енергетичну позицію краю рухливості для екситонів, локалізованих на флуктуаціях. У другому випадку систематично вивчений вплив зростання I не лише на екситонну, а й на пов'язану з домішками крайову люмінесценцію. На відміну від загальноприйнятих раніше уявлень, при збільшенні I аждо порогу руйнування не спостерігалося ніякого насичення інтенсивності крайової люмінесценції в об'ємних кристалах CdS. У той же час в епітаксійних шарах товщиною декілька мікронів таке насичення справді мало місце. Пропонується пояснення на якісному рівні, яке враховує дифузію (недифузійний транспорт) носіїв зі збудженого приповерхневого шару.

Ключові слова: люмінесценція, квантова яма, епітаксійний шар, екситон, ZnSe, CdS

PACS: $78.20 .-e$ 